\title{
Economies of Scale and Scope in the Sanitation Sector ${ }^{*}$
}

\author{
Claudio Ribeiro de Lucinda ${ }^{* *}$ \\ Francisco Anuatti ${ }^{* * *}$
}

\begin{abstract}
The recent water supply crisis in São Paulo showed the importance of regulation in the sanitation sector in the State of São Paulo. Therefore, this article aims to help in designing regulation by verifying the existence of economies of scale and of scope in the sanitation sector in São Paulo. For this, a database was constructed based on internal data from SABESP, together with operational data extracted from SNIS. The Evans and Heckman (1983) methodology was used with this database to evaluate economies of scale and of scope. The results enable us to conclude that the existence of diseconomies of scale is extremely rare in the cities served by SABESP. However, the evidence is weaker with relation to economies of scope. Nevertheless, in the vast majority of the cities served by SABESP, supplying water and sewerage services together within one company is cheaper than separating them between two companies focused on different services. In light of the results, we can conclude that initiatives that aim towards the structural separation of integrated water operators tend to generate inefficiencies on the production side, meaning supplying the services is less economical. These results are consistent with the international literature, which according to Abbott and Cohen (2009) indicates the existence of economies of scale up to a certain point, together with economies of scope in water and sewerage activities.
\end{abstract}

Keywords: Economies of scale; Economies of scope; Sanitation.

JEL codes: L23, L51.

Submitted in 13/03/2015. Revised in 17/07/2017.

Previous versions of the articles were supported by PITE/FAPESP Project 2010/50753-7.

** Contact Author. Associate Professor, Economics Department, FEA-RP. Email: claudiolucinda@usp.br. Claudio R. Lucinda is also grateful for the support of the CNPq Level 2 Research Productivity Scholarship.

*** Professor, Economics Department, FEA-RP. Email: fanuatti@usp.br. 


\section{Introduction}

The difficulties of supplying water in the São Paulo Metropolitan Region have shed light on the adequacy of the water and sewage regulation model in Brazil and especially in the State of São Paulo. One of the most important aspects in this regulation is the guarantee of productive efficiency; that is, the capacity to produce the good or service in the most economical way possible. In terms of productive structure, the production cycle in the basic sanitation sector begins with water collection, which can be done both in natural and man-made reservoirs. After water collection, the next steps are water treatment, distribution to consumption points (residential, industrial, or commercial), followed by disposal into a drainage network that may or may not be treated for returning into the natural cycle.

In Brazil, not all sanitation systems carry out these roles nor do they carry out these roles within the same company. This raises a question, which we intend to answer in this study: from an economic viewpoint, would it be more efficient for all of these stages to be carried out within a single company?

A subsidiary question, and related with the first, involves whether even if it is not efficient from an economic ${ }^{1}$ viewpoint for all the services to be provided by a single company, whether some subsets of services should or should not be provided together. These two questions can be rewritten more specifically as: Which services in the basic sanitation sector are subject to economies of scope?

Moreover, another important question involves so-called economies of scale, and the second important question in this project would be: What would be the minimum efficient scale for each one of these services?

The international literature on the topic is a little more comprehensive, with a review in Abbott and Cohen (2009). Specifically in relation to economies of scale, the authors show that the literature indicates the existence of economies of scale in water distribution up to a certain point, from which unit costs start to rise. There is no consensus in the literature regarding this point, with it depending on how the product variable is defined. As for sewage treatment and collection activities, the literature is more consensual, with results showing the existence of economies of

1 Efficiency understood here as the capacity to carry out these services at the lowest economic costs possible. 
scope. With regards to the economies of scope, Abbott and Cohen (2009) indicate that there is no evidence that separating activities in the sector creates advantages in terms of efficiency and productivity for small companies in the sector.

This article contributes to the literature summarized there by considering production units with different scales and integration arrangements, and not only small companies in the sector. Moreover, the study is pioneering in the sense that it provides an analysis for a large emerging market with serious problems of water and sewerage service coverage.

Both the question regarding economies of scope and the one involving economies of scale are especially relevant both from a regulatory viewpoint and from a competition viewpoint.

This point is especially important in light of the confused regulatory structure for the sanitation sector in Brazil, partly due to the regulatory and institutional changes that have occurred over the last 50 years. According to da Motta and Moreira (2004), until the beginning of the 1970s municipalities were obliged to supply water and sanitation services, coordinated by a federal body called the National Health Foundation (Funasa).

In 1971, even though the jurisdiction for supplying sanitation services continued to be municipal, important changes began to take place, with the National Plan for Sanitation (Planasa). With this plan, the States constituted sanitation companies under their management, funded by the National Housing Bank (BNH), and the municipalities were encouraged to concede the services to these state companies.

Also according to da Motta and Moreira (2004) the BNH resources and state funds initially provided a large portion of the sector's financing, with the expectation being that in the long run the tariff revenues would go on to support the system. However, from the middle of the 1980s the system faced serious problems in various aspects. The first of these were the serious funding problems of the public authorities at the beginning of the 1980s due to the debt crisis, combined with a high inflation rate in the same period. These effects led to the funding system implicit in the breakdown of the Planasa - the BNH was eventually closed down and the Caixa Economica Federal, which assumed its attributions, experienced serious difficulties in providing resources for the sector. 
The second problem was in managing the state companies. In many cases, the state companies for basic sanitation were used politically, leading to serious efficiency problems in the use of resources.

Together with this, the 1988 Constitution created additional uncertainties. At the same time the municipalities' power to concede water and sanitation services of a "local" character was reaffirmed, the efficient and well-regulated provision of water and sewerage services became the obligation of state and federal governments.

One of the classic arguments for continued government intervention in the decision-making process of economic agents in the form of regulation is the existence of so-called "market failures". Within these market failures, in which the competition between companies for consumers would not lead to optimal results from a social well-being viewpoint, the most well-known is the so-called "natural monopoly". According to Viscusi (2005), a natural monopoly would be a situation in which the production of a good or service by a single company would minimize its cost. Thus, by us determining the existence of economies of scale and scope, as well as for which production volumes of different services these characteristics arise, reasons would be provided for the continued regulation of the services, as well as justifying less government intervention in others.

Besides public policies, this article also generates academic dividends, in that it would be an unprecedented application of a methodology already established in cost function studies and analyses in the sanitation sector in Brazil. Most of the existing studies $^{2}$ on the topic in Brazil focus on the difference in efficiency between types of operators and none, up until now, have investigated one of the basic reasons for the existing regulatory structure in Brazil: economies of scale and of scope.

\section{Conceptual Framework}

We can describe the sanitation industry as beginning with water collection in reservoirs, which is subsequently treated and distributed. After distribution, the water is disposed of in a drainage system and finally returned into the natural cycle.

According to Tebbutt (1998), we can detail the activities in the following way:

2 Sriptore (2010), A Parceria público-privada no saneamento básico brasileiro: uma proposta para o desenvolvimento do setor. Master's Dissertation. FEARP/USP. Presents an updated review of the bibliography in Brazil. 
1. Water Collection and Storage: Although fresh, the water that is stored in natural reservoirs is known as raw water. The reason for the different terminology is that raw water presents a high risk of pollution due to human and animal activities. Since the regions in which the demand for water is higher rarely have a sufficient amount of natural reservoirs to meet the demand, reservoirs or other systems for storing more water need to be built. These reservoirs also help to wash the water by settling suspended solids. Also within this service, another important activity is transportation to treatment installations, which depending on the location of the reservoir and the treatment plants can require substantial costs in fixed assets and/or operating costs (energy).

2. Raw Water Treatment: This process covers different processes, such as sifting and adding products to adjust the water $\mathrm{Ph}$, as well as eliminating residues of chemical products and remaining odors in the water. It also includes solid removal processes via flotation or sedimentation, filtration, disinfection, and reduction of calcium carbonate in the water.

3. Water distribution and return: After being treated, the water needs to be transported to reservoirs whose role is to meet fluctuations in demand during the day, due to both different usage patterns in the day and in response to possible interruptions to the supply during the previous steps. Besides these reservoirs, there needs to be a considerable capillary distribution network, as well as a network of drainage channels to deal with water disposal. This disposal is increased with rainwater drainage, which plays the additional role of preventing flooding.

4. Sewage treatment and returning into the natural cycle: treating sewage is usually more expensive and laborious than treating raw water. The process begins with separating solids contained in the water using sieves, and the settling process to remove the sand. The next step is the use of microorganisms to dissolve the organic material in the sewage. If necessary, an additional stage can be employed to meet quality standards, depending on the characteristics of the sewage collected. It is important to note that at this point the water is not free of pollution, but can be returned into the natural cycle. 
Another important residue is the sludge resulting from the different stages in the process, which can be treated separately to free additional water and the dry residue that generates methane and fertilizer.

Another important conceptual question concerns how to adequately define economies of scale and scope, and with these definitions in mind, how to obtain reliable estimates of these measures.

A sector can be characterized as a Natural Monopoly if the sector's production - if carried out by a single company - is done at the lowest possible cost. That is, if in a particular market in order to provide a given volume of production there are various companies, the sum of their production costs would be higher than the costs that a possible monopolistic firm would incur in providing exactly the same amount alone compared to that of the sum of all the firms.

Or also: supposing $C(q)$ is the average cost associated with the production of a particular quantity q, this market would be characterized as being a natural monopoly if:

$$
C\left(q_{1}\right)+C\left(q_{2}\right)>C\left(q_{1}+q_{2}\right)
$$

in which both $q_{1}$ and $q_{2}$ represent two given volumes of the product. This cost function can represent the existence of significant economies of scale ${ }^{3}$. Until now, we have not allowed for the case that there is only one product, and the acquired inputs are used only for it. However, in most companies this is not true; with the same quantity of inputs, we can have two or more products or services being supplied in the market. In this section, we will discuss how we can extend the argument presented here to the case of joint production.

For this, first we will establish some categories of joint production. First, we can have joint production based on technical characteristics. These technical characteristics can be lucky enough that the production can be the result of common inputs - for example, the same classroom could be used to offer executive and degree courses, even though the services are carried out by different teachers. On the

3 For a more in-depth discussion of Economies of Scale, see Pindyck and Rubinfeld (2005). 
other hand, we could have the case that all the inputs are common in the process, and the process itself generates more than one product, which would be the case of common products. One example of this type of situation is alcohol production, which produces sub-products such as cane bagasse and vinasse, a product that if not treated properly is highly polluting.

These causes can be combined with the assumption of maximizing behavior by agents, so that the following multiproduct production function is generated. Let us suppose there are two products, called 1 and 2 . The multiproduct production function would thus be:

$$
\begin{aligned}
& Q_{1}=f\left(Q_{2}, K, L, M P, T, \ldots\right) \\
& Q_{2}=g\left(Q_{1}, K, L, M P, T, \ldots\right)
\end{aligned}
$$

in which $K, L, M P$ and $T$ denote the amount of capital, labor, raw material, and technologies available for the company as a whole. We can also determine the total cost and average cost functions in a multiproduct version. The only difference between them and their counterparts presented above is that instead of depending only on the quantity produced, they depend on the quantity of all the products and services provided. In this case, the functions would become $C T\left(Q_{1}, Q_{2}\right)$ e $C M e\left(Q_{1}, Q_{2}\right)$.

The total cost functions and average costs functions are also of special importance, as they show the so-called economies of scope. Generally, we observe economies of scope in a sector when the production cost of two - or more - services is lower when they are carried out by a single company than when they are carried out by separate companies. Using the same notation, we have economies of scope when:

$$
C T\left(Q_{1}, Q_{2}\right)<C T\left(Q_{1}, 0\right)+C T\left(Q_{2}, 0\right)
$$

In the same way that we have economies of scope, we can have diseconomies of scope, in which the total production cost of two or more products increases when they are supplied by the same company, in relation to what would be observed if production was carried out in separate companies. 
For the estimation of these measures itself, it is necessary to estimate cost or production functions. Since most of the time production functions are not directly observable, the most common way is to suppose functions which, depending on the estimated parameters, are able to capture the most basic characteristics in the company's production process. In general, these functions can be seen as linear expansions in parameters that can approximate an arbitrary function. This expansion can be viewed in the following way:

$$
f^{*}(\mathbf{x}) \approx f(\mathbf{x})=\sum_{i=1}^{N} a_{i} h^{i}(\mathbf{x})
$$

In which the $a_{i}$ are parameters, the $h^{i}$ are known functions and the $\mathbf{x}$ are variable vectors. If some conditions are satisfied for a given realization of the $\mathbf{x}^{*}$ vector, we can say that $f\left(\mathbf{x}^{*}\right)$ is an approximation of the true function at the point. And if besides this, it approximates the values of the first and second derivatives of the function as well, we would consider this to be a parsimonious and flexible functional form.

Additional care should be taken: when we are estimating a function like this with a database with an extensive domain - that is, with values that considerably map from the relevant quadrant of the $\mathrm{x}$ variable - it is highly probable that the function obtained will not be a second order approximation of the true production function at any point. Consequently, the resulting effects of the comparative statistic can be quite different from the results of the true function. That is, we can reject a hypothesis even when the true function would not reject it.

With relation to the costs function, a widely used function is the Translog. It takes the following functional form:

$$
\ln C=a_{0}+\sum_{i} \beta_{i} l n q_{i}+\sum_{j} \gamma_{j} l n r_{j}+\sum_{j} \sum_{k} \gamma_{j k} l n r_{j} l n r_{k}+\sum_{h} \sum_{i} \beta_{h i} l n q_{h} l n q_{i}+\sum_{i} \sum_{j} \phi_{i j} \ln q_{i} l n r_{j}
$$

In general, the variables are multiplied by 0.5 when we have the quadratic terms, to facilitate when compiling the factor demand systems. In addition, we will show 
how to construct a system of demands by factors of production using the Sheppard method:

$$
\frac{1}{C} \frac{\partial C}{\partial r_{i}}=\gamma_{i} \frac{1}{r_{i}}+\sum_{k} \gamma_{i k} \frac{\ln r_{k}}{r_{i}}+\sum_{l} \phi_{l i} \frac{\ln q_{l}}{r_{i}}
$$

Using the Sheppard method, $\frac{\partial C}{\partial r_{i}}=z_{i}$, that is:

$$
\begin{aligned}
& \frac{z_{i}}{C}=\frac{1}{r_{i}}\left[\gamma_{i}+\sum_{k} \gamma_{i k} \ln r_{k}+\sum_{l} \phi_{l i} \ln q_{l}\right] \\
& \frac{r_{i} z_{i}}{C}=\left[\gamma_{i}+\sum_{k} \gamma_{i k} \ln r_{k}+\sum_{l} \phi_{l i} \ln q_{l}\right]
\end{aligned}
$$

The left-hand side of the equation shows the share of the return from production factor $i$ in the total costs. For $N$ factors of production, we can have a system of $N-1$ equations, imposing the relevant constraints, in order to increase the efficiency of the estimates.

An interesting application in this sense was that of Evans and Heckman (1983), who aim to analyze the existence of economies of scale and scope in AT\&T. In the following sub-section we will provide more details of the approach used by these authors.

\subsection{The Evans and Heckman Approach}

The text from these authors, which is part of a collection dedicated to reviewing the economic studies carried out in the context of the structural separation action of the Bell System at the beginning of the 1980s, aims to investigate one of the necessary and sufficient conditions for a company to be considered a Natural Monopoly: the subadditivity of the costs function. To fulfill this aim, the authors point to the fact that cost function estimations based on an aggregate product measure do not necessarily lead to correct results from an economies of scale viewpoint. Only under some premises - which the authors claim are not verified in the context of the Bell System in the period in question - are the conclusions obtained based on the model in which the product measure is an aggregate of the individual product measures valid. 
Moreover, Evans and Heckman ${ }^{4}$ claim that even if an estimate of economies of scale using aggregate product measures is correct, it does not necessarily imply that all the component products or services of this aggregate also have economies of scale.

The first step in their analysis is to assume that the cost function of AT\&T is given by

$$
C=f(L, T, r, m, w, t)
$$

in which $L$ denoted the quantity of so-called local production, $T$ is the quantity of so-called long distance production, $w$ is the average wage, $r$ is the cost of capital, $m$ is the price of the raw materials, and $t$ is the rate of technological change. This separation between products is based on the idea that, at the time, these were the main products supplied by the company. Initially, they begin by estimating a translog costs function with the system of shares of the inputs in the total cost. In this study, they investigate two points. The first of these is whether the production function is separable in terms of products and the second is whether the costs function is additive. The first hypothesis, separability in terms of products, if it is true, implies that the decision regarding the amount to be produced can be separated from the decision regarding the composition of the quantity. If it is valid, we can aggregate the quantities of $L$ and $T$ in a single index, in the following way:

$$
C=f(L, T, r, m, w, t)=f(A(L, T), r, m, w, t)=f\left(Q^{*}, r, m, w, t\right)
$$

where $Q^{*}=A(L, T)$. For this to be valid, we must have $\rho_{i k} \beta_{l}=\rho_{i l} \beta_{k}, \forall i, k \neq l$. The second testable hypothesis, that of additivity, is that the cost of producing all of the products in the same place is equal to the sum of the costs of producing in separate units, that is:

$$
C=f(L, T, r, m, w, t)=C_{L}(L, r, m, w, t)+C_{T}(T, r, m, w, t)
$$

4 This original article opened up the way for two others, published in the American Economic Review (Evans and Heckman, 1984, 1986). In this text, we will stick to Evans and Heckman (1983). 
This additivity can be tested by the following hypothesis, in the translog function: $\delta_{k l}=-\beta_{k} \beta_{l}$. If this constraint is valid, the company does not have economies or diseconomies of scope. Finally, they aim to test the existence of economies of scope. The canonical test of economies of scope was proposed by Panzar (1989) and takes the following form. Let $\hat{T}$ be a subset of the space of products $(\hat{T}, T)$, at the point in which the quantity produced is $y$. The degree of economies of scope, in this case is given by:

$$
S C=\frac{C\left(y_{T}\right)+C\left(y_{\hat{T}}\right)-C(y)}{C(y)}
$$

in which $y_{T}$ is the quantity produced of the subset of products $T, y_{\hat{T}}$ is the quantity produced of the subset of products $\hat{T}$. The cost function would present economies of scope if $S C$ is greater than zero. Moreover, in the context of the authors' analysis, besides economies of scale, it is necessary to investigate the existence of economies of scope. The existence of economies of scope is a necessary but not sufficient condition for subadditivity in the costs function. That is, if there are not economies of scope, two companies each producing one of the services would do so for lower costs than a single one making both products.

However, this "canonical" methodology presents problems when applied to the translog function. With the coefficients in question, we could only calculate the values of $C\left(y_{T}\right)$ and $C\left(y_{\hat{T}}\right)$ if we supposed the values of some quantities equal to zero. However, as a simple inspection of the formula above can show us, this type of function is not defined at the points in which the arguments are equal to zero.

Evans and Heckman follow a different path, by testing a simpler hypothesis of whether the joint-production of the two goods within one company in this case, AT\&T - is more economical than in two separate companies. Their study does the following. It considers $\mathbf{Q}_{t}^{*}=\left(Q_{1 t}^{*}, Q_{2 t}^{*}\right)$ as the vector of goods produced in a particular year $t$. Moreover, it also considers the vector $\mathbf{Q}_{M}=\left(Q_{1 M}, Q_{2 M}\right)=\left(\min Q_{1 t}^{*}, \min Q_{2 t}^{*}\right)$, which are the lowest values of the two products available in the sample. Let us consider two hypothetical companies, A and $\mathrm{B}$, which produce the following quantities:

$$
\mathbf{Q}_{A t}=\left(\phi Q_{1 t}+Q_{1 M}, \omega Q_{2 t}+Q_{2 M}\right)
$$




$$
\mathbf{Q}_{B t}=\left((1-\phi) Q_{1 t}+Q_{1 M},(1-\omega) Q_{2 t}+Q_{2 M}\right)
$$

In this case, $\omega$ and $\phi$ belong to an interval $[0,1]$, since the quantity observed would be equal to the production of the two hypothetical companies ${ }^{5}$. Restricting the function domain to the observed values, the two companies together produce:

$$
\begin{aligned}
& Q_{1 t}+2 Q_{1 M}=Q_{1 t}^{*} \\
& Q_{2 t}+2 Q_{2 M}=Q_{2 t}^{*}
\end{aligned}
$$

The authors restrict the analysis to the years in which $Q_{1 t}>Q_{1 t}^{*}-2 Q_{1 M}$ and $Q_{2 t}>Q_{2 t}^{*}-2 Q_{2 M}$. Moreover, another condition set by them is that each hypothetical company produces the quantities of goods in proportions between the minimum and maximum observed in the data. This imposed condition aims to prevent the coefficients of the translog function from being used to generate cost estimates for very distant hypothetical quantities from those observed in the data sample.

Finally, consider the following definitions:

$$
\begin{gathered}
C_{A t}(\phi, \omega)=C\left(\mathbf{Q}_{A t}\right) \\
C_{B t}(\phi, \omega)=C\left(\mathbf{Q}_{B t}\right) \\
C_{t}^{*}=C\left(\mathbf{Q}_{t}^{*}\right)
\end{gathered}
$$

These are the levels of costs for the two companies, $A$ and $B$, with the previously estimated coefficients and the quantity produced for each hypothetical company of each one of the products. $C_{A t}$ and $C_{B t}$ are functions of $\phi$ and $\omega$ for $\mathbf{Q}_{A t}$ and $\mathbf{Q}_{B t}$ are constructed via these coefficients. The subadditivity will be obtained by calculating the following statistic for each one of the products:

$$
\operatorname{Sub}(\phi, \omega)=\frac{C_{t}^{*}-C_{A t}(\phi, \omega)-C_{B t}(\phi, \omega)}{C_{t}^{*}}
$$

5 The authors' intuition is to avoid conclusions for out-of-sample production configuration. 
We can note that this statistic is still a function of $\phi$ and $\omega$. In this case, what the authors do is estimate the value of this statistic for all of the possible parameters $\phi$ and $\omega^{6}$, and if the maximum of this value is negative (hat is, equal to (-1) multiplying the previous $S C$ statistic) and significant ${ }^{7}$, we can say that there are economies of scope and subadditivity of the costs function.

In their article, Evans and Heckman (1983) indicate that at no point in the time period whose data enable the analysis - between 1958 and 1977 - were the results shown to be significant and negative, thus rejecting the hypothesis of the existence of economies of scale.

\subsection{Economies of Scale and Scope after Evans and Heckman}

Undoubtedly, the work of Evans and Heckman became a reference with regards to the topic of estimating economies of scale and of scope. The big question in the literature after the apparently counter-intuitive conclusion of the absence of subadditivity in the costs function was whether the cost function estimated by Evans and Heckman fulfilled the "regularity conditions" in the space of product configurations in which they carry out the test described in the previous section.

With regards to the aforementioned "regularity conditions", more specifically the tests focus on:

\section{Positive Marginal Costs}

\section{Positive Total Cost Values}

3. Non-decreasing Total Cost in the quantity produced.

In 1991, the results from Evans and Heckman came under criticism from Diewert and Wales (1991), who pointed out a problem with the estimates of the translog costs function. More specifically, the costs function that the authors estimate is decreasing in the quantity produced for an interval of data from the sample - in other words, the estimated function would imply that, with an increase in the quantities

6 In practice, in a grid of points with a difference of 0.1 between them.

7 The authors do not say how they derive the standard errors of this statistic. However, the correct way would be to apply the Delta Method. 
produced, the company's total costs would reduce, in contradiction of what would be expected from microeconomic theory. This would place all of the implications of the subadditivity tests of the costs function under suspicion.

Another criticism also concerning the point of the regularity conditions is the one from Roller (1990). In his article, the author begins by mentioning the regularity problems of the costs function, subsequently proposing a solution involving a functional form that, by construction, fulfills the regularity conditions in a wider space of quantities. The author himself recognizes, in this study, that this means testing the existence of subadditivity in the costs function is more difficult, which makes the process of constructing the functional form more complex.

The functional form that the author uses is the so-called quadratic CES function, which is an interaction between a defined CES involving the prices of the factors of production and a quadratic function in the prices of the factors. On top of this function he sets the constraints of (a) non-negativity and (b) monotonocity. The constraints are non-linear, which makes the traditional test procedures more difficult to carry out, resulting in him placing a penalty function in the objective function of the estimation. Applying this methodology with the same data as Evans and Heckman would indicate that, yes, there are economies of scale and scope for AT\&T before the structural separation.

The third criticism along these lines is from Salvanes and Tjøtta (1998), who refine the area where the Evans and Heckman subadditivity test is calculated, selecting where the quantities would generate values for the cost function that would fulfill the regularity conditions. However, as in Diewert (1971), the authors find that the function presented negative marginal costs in a good portion of the region.

Besides these three studies, there are a series of other articles indicating problems with the methodology, but which are less relevant for understanding the subsequent literature. The first of them is a note in the American Economic Review by Sueyoshi and Anselmo (1986), who better define the limits of the region where the subadditivity test of the costs function must be carried out.

The second critical paper was that of Charnes et al. (1988), who affirm that (i) there are problems with the data used by Evans and Heckman and (ii) the use of a different estimation method - Constrained Regression - generates different results 
regarding the existence of economies of scale. Evans and Heckman (1988) answer that they used different data from Charnes et al. (1988), and that with the use of the same data the Constrained Regression methodology generates the same conclusions.

Finally, Shin and Ying (1992) indicate the inherent limitation of the data sample used by Evans and Heckman, which was a time series of factor of production prices and quantities. In order to overcome this problem, they use a panel of local operators - post AT\&T structural separation. They conclude that, with this larger sample of data, there is apparently no evidence of subadditivity.

In any case, this bibliographical review indicates the following care in estimating cost functions. First, it would be desirable to obtain the widest data sample possible, considering that the companies have the same access to technology ${ }^{8}$. This larger sample increases the number of degrees of freedom available, enabling more precise tests.

Second, it appears to be essential to check the regularity conditions of the estimated costs function to avoid negative marginal cost estimates. This would result in problems for all of the conclusions of subadditivity of the costs function and for the conclusions of economies of scale and scope.

\section{Empirical Analysis}

\subsection{Database}

The database used in the subsequent section was constructed based on the financial and operational information provided by SABESP, together with the information retrieved from SNIS (National Information System for Sanitation). Information was gathered regarding the following variables from the income statement:

These data are on a weekly basis and disaggregated for the 536 municipal codes and business units. In terms of periodicity, we have a weekly database of this

8 Note, however, that this does not mean that all of the observations have to be of companies that effectively use this technology; it is perfectly possible that differences in the factor of production prices lead to different choices of production processes. 
Table 1

Income Statement Items

\begin{tabular}{l}
\hline Key \\
\hline CENTRAL ADMIN. \\
CREDIT PAYMENTS \\
COFINS / PASEP \\
DEPR./AMORTZ. \\
DIRECT \\
ELECTRICITY \\
FINANCIAL \\
GENERAL \\
INDIRECT \\
MATERIALS \\
PERSONNEL \\
PRODUCTION \\
OPERATION ADMIN. \\
OPERATING EXPENSES \\
OPERATING INCOME \\
OPERATING REVENUES \\
SERVICES \\
TAX \\
MAT. TREATMENT
\end{tabular}

information, from the first semester of 2007 to the second semester of $2011^{9}$. In terms of operational information, the following data were collected:

1. Total Billed Connections - Water

2. Total Billed Connections - Sewage

3. Total Billed Economies - Water

4. Total Billed Economies - Sewage

5. Volume of Water Produced (by Water Treatment Station)

6. Volume of Sewage Collected

7. Volume of Sewage Treated

8. Quantity of Sewage Spillages

9 We are grateful for the valuable collaboration from the SABESP team, especially the FCP staff and the engineer Marcelo Miki. Additional information regarding directly operational fixed and permanent assets was also obtained via the same team. 
9. Duration of Spillages

Finally, in the SNIS system, the following variables were obtained:

1. BL001 - Current Assets

2. BL002 - Total Assets

3. PES050 - Personnel Occupied in the Alternative Systems

4. FN026 - Total Quantity of Own Employees

Based on this primary database, a subset of information was selected, whose names and codes are in the list below:

- cen_adm_exp - central administration expenses

- op_adm_exp - operational administration expenses

- cred_pmt_exp - credit payment expenses

- dep_exp - depreciation/amortization expenses

- $f$ in_exp - financial expenses

- tax_exp - tax expenses

- ele_exp - electricity expenses

- general_exp - general expenses

- mattr_exp - material treatment expenses

- mat_exp - material expenses

- ser_exp - service expenses

- tc - total cost, sum of all expenses

- vol_cl_sew - volume of sewage collected

- vol_tr_sew - volume of sewage treated 
- vol_prd_wat - volume of water produced

- qt_emp - total quantity of own employees

- tcee_wat - total consumption of electricity in the water systems

- tcee_sew - total consumption of electricity in the sewage systems.

Assets: both assets were constructed by inserting the total sum of assets (extracted from SNIS) assessed for the municipalities using the participation of the municipalities in the total water and sewage connections (present in SNIS).

- ca - current assets.

- ta - total assets.

Based on these values, the returns data were constructed for the factors of production, in the following ways:

- ret_1 - return on labor. Sum of personnel, central, and operational admin expenses, divided by the quantity of employees.

- ret_k - return on capital. Sum of depreciation/amortization expenses, credit payment expenses, and financial expenses, divided by total assets.

- ret_m - return on inputs. Sum of electricity expenses divided by the total consumption of electricity by water and sewage systems.

In terms of geographical representativeness, figure 1 illustrates for which municipalities of the State of Sao Paulo we have available information.

Table 2 shows some characteristics of the variables constructed in the following way:

We can note that, in some municipality/pairs, we observe negative costs. These observations will be ignored in the subsequent analysis. Another point worth noting is the average value of the return on labor, in the order of 93 thousand reais per semester, which includes labor costs. That is, the values shown here are in accordance with the expectation.

We therefore move on to the econometric analysis itself. 
Figure 1

Data Availability by Municipality

Municipalities of the State of São Paulo with Data

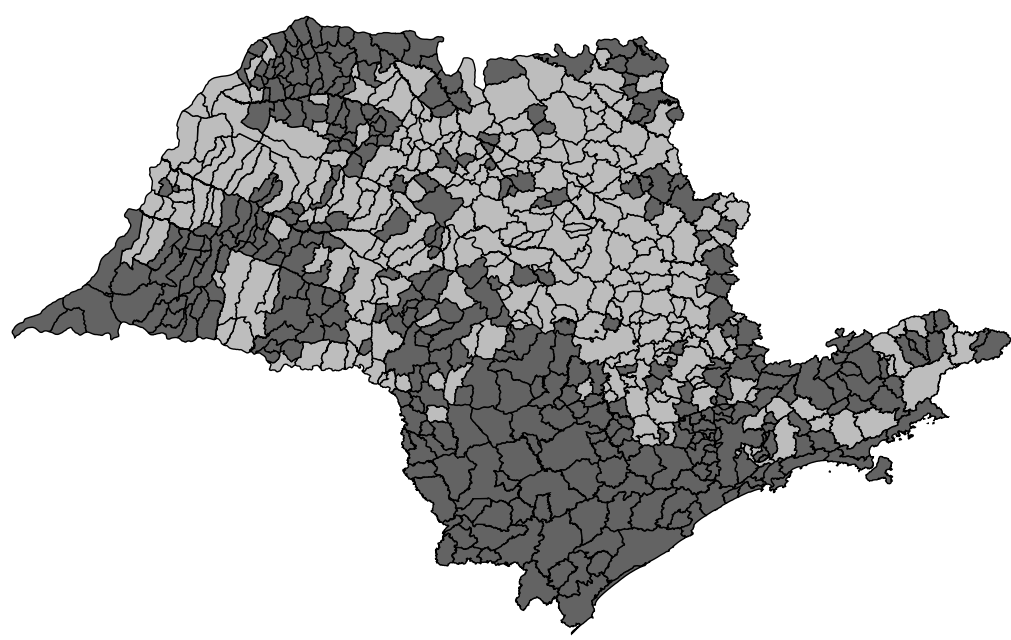

Dark Gray-Available Data

Table 2

Descriptive Statistics

\begin{tabular}{lccccc}
\hline & $\mathrm{N}$ & Mean & Maxim & Minimu & St. Dev. \\
\hline Total Cost & 1650 & 982554.1 & $3.26 \mathrm{e}+07$ & -320241.1 & 2360022 \\
Vol Sewage Collected & 1650 & 590388.4 & $1.50 \mathrm{e}+07$ & 22576.86 & 1453303 \\
Vol Sewage Treated & 1650 & 441488.6 & $1.50 \mathrm{e}+07$ & 0 & 1210017 \\
Vol Water Produced & 1650 & 1633381 & $3.04 \mathrm{e}+07$ & 37087 & 3664556 \\
Ret. L & 1650 & 192377 & 936080.2 & 13409.72 & 100915 \\
Ret. Kl & 1650 & 6.163065 & 67.87537 & .0498552 & 4.685057 \\
Ret. Mat & 1650 & 457.3275 & 2397.824 & 18.57634 & 221.9534 \\
\hline
\end{tabular}

\subsection{Econometric Analysis}

In the econometric analysis, we will follow the estimate of a translog function for total cost, followed by the replica of the analysis from Evans and Heckman (1983) to investigate the existence of economies of scale and of scope. In the econometric analysis, we will make some variations. Initially, we will estimate a simpler form of cost function, that of Cobb and Douglas (1928), followed by the translog ver- 
sion. Here, alternatives will also be investigated with and without semester dummy variables. The translog function to be estimated here takes the following form:

$$
\begin{gathered}
C=\alpha_{0}+\sum_{i=1}^{N} \alpha_{i} \ln p_{i}+\sum_{k=1}^{M} \beta_{k} \ln q_{k}+\mu \ln t \\
+\left[\sum_{i=1}^{N} \sum_{j=1}^{N} \gamma_{i j} \ln p_{i} \ln p_{j}+\sum_{k=1}^{M} \sum_{l=1}^{M} \delta_{k l} \ln q_{k} \ln q_{l}\right]+ \\
+\sum_{i=1}^{N} \sum_{k=1}^{M} \rho_{i k} \ln p_{i} \ln p_{k}+\sum_{i=1}^{M} \lambda_{i} \ln p_{i} \ln t+\sum_{k=1}^{N} \theta_{k} \ln q_{k} \ln t+\tau(\ln t)^{2}
\end{gathered}
$$

Based on the coefficients above, we also have the following functional form for the equations for the share of the factors of production in the costs:

$$
S_{i}=\frac{p_{i} x_{i}}{C}=\alpha_{i}+\sum_{i} \gamma_{i j} \ln p_{j}+\sum_{k} \rho_{i k} \ln q_{k}+\lambda_{i} \ln t
$$

Moreover, the version in which the translog costs equation is estimated will be investigated together with a system of equations corresponding to the shares of the returns from the factors of production in the total cost. In this case, the literature recommends investigating the imposition of constraints between the equations, with the aim of increasing their efficiency. In the table 3 we thus begin with the results of the Cobb-Douglas and the Translog function without the inclusion of the semester dummy variables.

In the case of the results in table 3, the Cobb-Douglas functions are the ones that generate more directly interpretable coefficients; although the constraints involved with the estimation of the function are so many that we are unlikely to reach economically interesting conclusions with these coefficients alone. However, what the Cobb-Douglas estimates indicate is that the costs function presents unit elasticity with relation to the volume of water produced, and negative cost elasticity with relation to the volume of (collection and treatment) costs.In table 4 the results of the translog function are shown, with and without the system of factor shares.

In these results, the coefficients are not directly interpretable, but we can note two important points, in terms of the significance of the results. First, the significant 
Table 3

Single Equation Models

\begin{tabular}{|c|c|c|c|c|c|c|}
\hline & $\begin{array}{c}\mathrm{MQO} \\
\mathrm{b} / \mathrm{t}\end{array}$ & & $\begin{array}{c}\mathrm{MQO} \\
\mathrm{b} / \mathrm{t}\end{array}$ & & $\begin{array}{c}\text { TL-OLS } \\
\mathrm{b} / \mathrm{t}\end{array}$ & \\
\hline Log(Vol Sewage Collected) & $\begin{array}{c}-0.0940 \\
(-2.2779)\end{array}$ & $*$ & $\begin{array}{c}-0.1734 \\
(-4.0515)\end{array}$ & $* * *$ & $\begin{array}{c}-1.4544 \\
(-0.8370)\end{array}$ & \\
\hline Log(Vol Sewage Treated $)$ & $\begin{array}{l}-0.0108 \\
(-0.4945)\end{array}$ & & $\begin{array}{c}-0.0224 \\
(-1.0827)\end{array}$ & & $\begin{array}{c}-0.2033 \\
(-0.2396)\end{array}$ & \\
\hline Log(Vol Water Produced) & $\begin{array}{c}1.0207 \\
(32.4005)\end{array}$ & $* * *$ & $\begin{array}{c}1.0577 \\
(32.9637)\end{array}$ & $* * *$ & $\begin{array}{c}1.8194 \\
(1.4784)\end{array}$ & \\
\hline $\log ($ Ret. MO) & $\begin{array}{c}0.7015 \\
(12.8640)\end{array}$ & $* * *$ & $\begin{array}{c}0.2270 \\
(2.8707)\end{array}$ & $* *$ & $\begin{array}{c}-2.0394 \\
(-0.6242)\end{array}$ & \\
\hline $\log ($ Ret. Kl) & $\begin{array}{c}0.1111 \\
(3.6233)\end{array}$ & $* * *$ & $\begin{array}{c}0.1070 \\
(3.5989)\end{array}$ & $* * *$ & $\begin{array}{c}2.4920 \\
(2.5931)\end{array}$ & $* *$ \\
\hline Log(Ret. Mat) & $\begin{array}{c}0.2243 \\
(4.9540)\end{array}$ & $* * *$ & $\begin{array}{c}0.1489 \\
(3.7096)\end{array}$ & $* * *$ & $\begin{array}{c}1.3078 \\
(0.7443)\end{array}$ & \\
\hline Log(Vol Sewage Collected $) 2$ & & & & & $\begin{array}{c}0.2128 \\
(3.1070)\end{array}$ & $* *$ \\
\hline Log(Vol Sewage Treated $) 2$ & & & & & $\begin{array}{c}-0.0289 \\
(-0.9843)\end{array}$ & \\
\hline $\log ($ Vol Water Produced $) 2$ & & & & & $\begin{array}{c}-0.1218 \\
(-3.1313)\end{array}$ & $* *$ \\
\hline $\log (\text { Vol Sewage Collected })^{*} \log ($ Vol Sewage Treated $)$ & & & & & $\begin{array}{c}-0.1677 \\
(-2.1962)\end{array}$ & $*$ \\
\hline Log(Vol Sewage Collected $)^{*} \log ($ Vol Water Produced $)$ & & & & & $\begin{array}{c}-0.1161 \\
(-1.2572)\end{array}$ & \\
\hline $\log (\text { Vol Sewage Collected })^{*} \log ($ Ret. MO $)$ & & & & & $\begin{array}{c}0.0444 \\
(0.2782)\end{array}$ & \\
\hline $\log (\text { Vol Sewage Collected })^{*} \log ($ Ret. Kl $)$ & & & & & $\begin{array}{c}-0.0836 \\
(-0.9043)\end{array}$ & \\
\hline $\log (\text { Vol Sewage Collected })^{*} \log ($ Ret. Mat $)$ & & & & & $\begin{array}{c}-0.1041 \\
(-0.8699)\end{array}$ & \\
\hline $\log (\text { Vol Sewage Treated })^{*} \log ($ Vol Water Produced $)$ & & & & & $\begin{array}{c}0.2186 \\
(3.4494)\end{array}$ & $* * *$ \\
\hline $\log (\text { Vol Sewage Treated })^{*} \log ($ Ret. MO) & & & & & $\begin{array}{c}0.0024 \\
(0.0251)\end{array}$ & \\
\hline $\log (\text { Vol Sewage Treated })^{*} \log ($ Ret. Kl $)$ & & & & & $\begin{array}{c}0.0220 \\
(0.4618)\end{array}$ & \\
\hline $\log (\text { Vol Sewage Treated })^{*} \log ($ Ret. Mat $)$ & & & & & $\begin{array}{c}-0.0156 \\
(-0.1961)\end{array}$ & \\
\hline Log(Vol Water Produced $)^{*} \log ($ Ret. MO) & & & & & $\begin{array}{c}0.0716 \\
(0.6918)\end{array}$ & \\
\hline $\log (\text { Vol Water Produced })^{*} \log ($ Ret. Kl $)$ & & & & & $\begin{array}{c}0.0349 \\
(0.5582)\end{array}$ & \\
\hline $\log (\text { Vol Water Produced })^{*} \log ($ Ret. Mat) & & & & & $\begin{array}{c}0.0472 \\
(0.6425)\end{array}$ & \\
\hline $\log ($ Ret. MO $) 2$ & & & & & $\begin{array}{c}0.0846 \\
(0.5737)\end{array}$ & \\
\hline $\log ($ Ret. Kl)2 & & & & & $\begin{array}{c}0.0656 \\
(3.5246)\end{array}$ & $* * *$ \\
\hline $\log ($ Ret. Mat $) 2$ & & & & & $\begin{array}{c}0.0550 \\
(1.5906)\end{array}$ & \\
\hline $\log (\text { Ret. MO })^{*} \log ($ Ret. Kl $)$ & & & & & $\begin{array}{c}-0.1863 \\
(-1.9348)\end{array}$ & \\
\hline $\log (\text { Ret. MO })^{*} \log ($ Ret. Mat $)$ & & & & & $\begin{array}{c}-0.0786 \\
(-0.5689)\end{array}$ & \\
\hline $\log (\text { Ret. Kl })^{*} \log ($ Ret. Mat $)$ & & & & & $\begin{array}{c}0.0039 \\
(0.0441)\end{array}$ & \\
\hline Constant & $\begin{array}{c}-9.4095 \\
(-15.7966)\end{array}$ & $* * *$ & $\begin{array}{c}-3.2014 \\
(-3.1981)\end{array}$ & $* *$ & $\begin{array}{c}6.0687 \\
(0.3279)\end{array}$ & \\
\hline Semester Dummies & No & & Yes & & No & \\
\hline $\begin{array}{l}\text { Observations } \\
\text { LR chi2 }\end{array}$ & $1.5 \mathrm{e}+03$ & & $1.5 \mathrm{e}+03$ & & $1.5 \mathrm{e}+03$ & \\
\hline Log-Lik. & $-1.2 \mathrm{e}+03$ & & $-1.1 \mathrm{e}+03$ & & $-1.2 \mathrm{e}+03$ & \\
\hline R2 Ajusted & 0.8565 & & 0.8738 & & 0.8627 & \\
\hline
\end{tabular}


Table 4

Multiple Equation Models

\begin{tabular}{|c|c|c|c|c|c|c|c|c|c|c|}
\hline & $\begin{array}{c}\text { TL-OLS-TD } \\
\mathrm{b} / \mathrm{t}\end{array}$ & & $\begin{array}{c}\text { SURE } \\
\mathrm{b} / \mathrm{t}\end{array}$ & & $\begin{array}{c}\text { SURE } \\
\mathrm{b} / \mathrm{t}\end{array}$ & & $\begin{array}{c}\text { SURE } \\
\mathrm{b} / \mathrm{t}\end{array}$ & & $\begin{array}{c}\text { SURE } \\
\text { b/t }\end{array}$ & \\
\hline \multicolumn{11}{|l|}{ Eq Costs } \\
\hline Log(Vol Sewage Collected) & $\begin{array}{l}-2.2981 \\
(-1.3703)\end{array}$ & & $\begin{array}{c}-1.1727 \\
(-0.7342)\end{array}$ & & $\begin{array}{l}-1.9286 \\
(-1.2742)\end{array}$ & & $\begin{array}{l}-2.1465 \\
(-1.0865)\end{array}$ & & $\begin{array}{c}-2.5779 \\
(-1.3525)\end{array}$ & \\
\hline Log(Vol Sewage Treated $)$ & $\begin{array}{c}0.0807 \\
(0.0966)\end{array}$ & & $\begin{array}{c}-0.2522 \\
(-0.2729)\end{array}$ & & $\begin{array}{c}0.0060 \\
(0.0069)\end{array}$ & & $\begin{array}{c}-0.1596 \\
(-0.1424)\end{array}$ & & $\begin{array}{c}-0.0852 \\
(-0.0788)\end{array}$ & \\
\hline Log(Vol Water Produced $)$ & $\begin{array}{c}2.3180 \\
(2.0321)\end{array}$ & * & $\begin{array}{c}1.6544 \\
(1.5514)\end{array}$ & & $\begin{array}{c}2.0970 \\
(2.0748)\end{array}$ & * & $\begin{array}{c}3.1224 \\
(2.3596)\end{array}$ & * & $\begin{array}{c}3.3319 \\
(2.6094)\end{array}$ & ** \\
\hline Log(Vol Sewage Collected)2 & $\begin{array}{c}0.2268 \\
(3.0989)\end{array}$ & $* *$ & $\begin{array}{c}0.2320 \\
(2.6048)\end{array}$ & ** & $\begin{array}{c}0.2473 \\
(2.9316)\end{array}$ & ** & $\begin{array}{c}0.2083 \\
(1.8509)\end{array}$ & & $\begin{array}{c}0.2138 \\
(1.9731)\end{array}$ & * \\
\hline Log(Vol Sewage Treated $) 2$ & $\begin{array}{c}-0.0292 \\
(-1.0247)\end{array}$ & & $\begin{array}{c}-0.0260 \\
(-0.7865)\end{array}$ & & $\begin{array}{c}-0.0242 \\
(-0.7715)\end{array}$ & & $\begin{array}{c}-0.0381 \\
(-0.8922)\end{array}$ & & $\begin{array}{c}-0.0440 \\
(-1.0693)\end{array}$ & \\
\hline Log(Vol Water Produced $) 2$ & $\begin{array}{l}-0.1118 \\
(-2.9903)\end{array}$ & ** & $\begin{array}{c}-0.0845 \\
(-2.1869)\end{array}$ & * & $\begin{array}{l}-0.0766 \\
(-2.0919)\end{array}$ & * & $\begin{array}{l}-0.0906 \\
(-1.8083)\end{array}$ & & $\begin{array}{l}-0.0870 \\
(-1.8018)\end{array}$ & \\
\hline $\log ($ Vol Sewage Collected $) * \log ($ Vol Sewage Treated $)$ & $\begin{array}{c}-0.1761 \\
(-2.2576)\end{array}$ & $*$ & $\begin{array}{c}-0.1613 \\
(-1.7064)\end{array}$ & & $\begin{array}{c}-0.1756 \\
(-1.9580)\end{array}$ & & $\begin{array}{c}-0.1601 \\
(-1.3227)\end{array}$ & & $\begin{array}{c}-0.1497 \\
(-1.2834)\end{array}$ & \\
\hline Log(Vol Sewage Treated $) * \log ($ Vol Water Produced $)$ & $\begin{array}{l}-0.1177 \\
(-1.2439)\end{array}$ & & $\begin{array}{c}-0.1807 \\
(-1.6391)\end{array}$ & & $\begin{array}{c}-0.1812 \\
(-1.7371)\end{array}$ & & $\begin{array}{c}-0.1542 \\
(-1.0908)\end{array}$ & & $\begin{array}{c}-0.1484 \\
(-1.0903)\end{array}$ & \\
\hline $\log (\text { Vol Sewage Collected })^{*} \log ($ Ret. MO $)$ & $\begin{array}{l}0.1022 \\
(0.6583)\end{array}$ & & $\begin{array}{c}0.0633 \\
(0.4313)\end{array}$ & & $\begin{array}{c}0.1122 \\
(0.8063)\end{array}$ & & $\begin{array}{c}0.1441 \\
(1.0747)\end{array}$ & & $\begin{array}{c}0.1474 \\
(1.1378)\end{array}$ & \\
\hline $\log ($ Vol Sewage Collected $){ }^{*} \log ($ Ret. Kl $)$ & $\begin{array}{c}-0.1130 \\
(-1.2641)\end{array}$ & & $\begin{array}{c}-0.0782 \\
(-0.8525)\end{array}$ & & $\begin{array}{l}-0.1038 \\
(-1.1968)\end{array}$ & & $\begin{array}{c}-0.1891 \\
(-1.6585)\end{array}$ & & $\begin{array}{c}-0.1904 \\
(-1.7333)\end{array}$ & \\
\hline $\log (\text { Vol Sewage Collected })^{*} \log ($ Ret. Mat $)$ & $\begin{array}{l}-0.1248 \\
(-1.1175)\end{array}$ & & $\begin{array}{c}-0.1304 \\
(-0.9970)\end{array}$ & & $\begin{array}{l}-0.1452 \\
(-1.1714)\end{array}$ & & $\begin{array}{l}-0.0532 \\
(-1.5247)\end{array}$ & & $\begin{array}{c}-0.0538 \\
(-1.5514)\end{array}$ & \\
\hline Log(Vol Sewage Treated $) * \log ($ Vol Water Produced $)$ & $\begin{array}{c}0.2122 \\
(3.1648)\end{array}$ & ** & $\begin{array}{c}0.2101 \\
(2.8279)\end{array}$ & $* *$ & $\begin{array}{c}0.2076 \\
(2.9512)\end{array}$ & ** & $\begin{array}{c}0.2229 \\
(2.3515)\end{array}$ & * & $\begin{array}{c}0.2083 \\
(2.2819)\end{array}$ & * \\
\hline $\log (\text { Vol Sewage Treated })^{*} \log ($ Ret. MO $)$ & $\begin{array}{l}-0.0236 \\
-0.02522)\end{array}$ & & $\begin{array}{c}0.0077 \\
(0.0814)\end{array}$ & & $\begin{array}{l}-0.0160 \\
(-0.1790)\end{array}$ & & $\begin{array}{c}-0.0075 \\
(-0.0980)\end{array}$ & & $\begin{array}{c}0.0012 \\
(0.0163)\end{array}$ & \\
\hline Log(Vol Sewage Treated $)^{*} \log ($ Ret. Kl) & $\begin{array}{l}0.0324 \\
(0.7038)\end{array}$ & & $\begin{array}{c}0.0167 \\
(0.3283)\end{array}$ & & $\begin{array}{l}0.0273 \\
(0.5658)\end{array}$ & & $\begin{array}{c}-0.0110 \\
(-0.1716)\end{array}$ & & $\begin{array}{c}-0.0052 \\
(-0.0846)\end{array}$ & \\
\hline Log(Vol Sewage Treated $)^{*} \log ($ Ret. Mat $)$ & $\begin{array}{l}0.0194 \\
(0.2483)\end{array}$ & & $\begin{array}{c}-0.0229 \\
(-0.2594)\end{array}$ & & $\begin{array}{c}0.0072 \\
(0.0861)\end{array}$ & & $\begin{array}{l}0.0161 \\
(07972)\end{array}$ & & $\begin{array}{c}0.0180 \\
(0.8985)\end{array}$ & \\
\hline $\log ($ Vol Water Produced $){ }^{*} \log ($ Ret. MO $)$ & 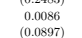 & & $\begin{array}{c}(-10.25959) \\
0.0559 \\
(0.6096)\end{array}$ & & $\begin{array}{l}-0.0010 \\
-0.0116) \\
(-0.016)\end{array}$ & & $\begin{array}{c}-0.0963 \\
(-1.0620)\end{array}$ & & $\begin{array}{c}-0.1104 \\
(-1.2577)\end{array}$ & \\
\hline $\log (\text { Vol Water Produced })^{*} \log ($ Ret. Kl $)$ & $\begin{array}{c}0.0692 \\
(1.1381)\end{array}$ & & $\begin{array}{c}0.0450 \\
(0.7356)\end{array}$ & & $\begin{array}{c}0.0743 \\
(1.2828)\end{array}$ & & $\begin{array}{c}0.1679 \\
(2.2085)\end{array}$ & * & $\begin{array}{c}0.1735 \\
(2.3659)\end{array}$ & * \\
\hline $\log ($ Vol Water Produced $){ }^{*} \log ($ Ret. Mat $)$ & $\begin{array}{c}0.0603 \\
(0.9277)\end{array}$ & & $\begin{array}{c}0.0808 \\
(1.0461)\end{array}$ & & $\begin{array}{c}0.0917 \\
(1.2492)\end{array}$ & & $\begin{array}{c}0.0447 \\
(1.8774)\end{array}$ & & $\begin{array}{c}0.0435 \\
(1.8361)\end{array}$ & \\
\hline $\log ($ Ret. MO) & $\begin{array}{c}-3.5561 \\
(-1.4842)\end{array}$ & & $\begin{array}{c}-1.9232 \\
(-1.6508)\end{array}$ & & $\begin{array}{c}-3.0726 \\
(-2.6133)\end{array}$ & ** & $\begin{array}{c}1.6246 \\
(1.1515)\end{array}$ & & $\begin{array}{c}-0.0251 \\
(-0.0172)\end{array}$ & \\
\hline $\log ($ Ret. Kl) & $\begin{array}{c}1.8930 \\
(2.2191)\end{array}$ & $*$ & $\begin{array}{c}1.8377 \\
(2.3990)\end{array}$ & * & $\begin{array}{c}1.3086 \\
(1.7878)\end{array}$ & & $\begin{array}{c}1.1283 \\
(1.1975)\end{array}$ & & $\begin{array}{c}0.9365 \\
(1.0142)\end{array}$ & \\
\hline Log(Ret. Mat) & $\begin{array}{l}1.1863 \\
(0.8192)\end{array}$ & & $\begin{array}{c}0.9119 \\
(0.8083)\end{array}$ & & $\begin{array}{c}0.7222 \\
(0.6648)\end{array}$ & & $\begin{array}{c}0.1223 \\
(0.3499)\end{array}$ & & $\begin{array}{c}-0.1252 \\
(-0.3506)\end{array}$ & \\
\hline Log(Ret. MO) 2 & $\begin{array}{c}0.1463 \\
(1.3941)\end{array}$ & & $\begin{array}{c}0.0654 \\
(1.3147)\end{array}$ & & $\begin{array}{c}0.1114 \\
(2.2628)\end{array}$ & * & $\begin{array}{c}-0.0538 \\
(-1.0738)\end{array}$ & & $\begin{array}{c}-0.0003 \\
(-0.0052)\end{array}$ & \\
\hline $\log ($ Ret. Kl $) 2$ & $\begin{array}{c}0.0520 \\
(3.0233)\end{array}$ & ** & $\begin{array}{c}0.0636 \\
(3.9817)\end{array}$ & $* * *$ & $\begin{array}{c}0.0505 \\
(3.3085)\end{array}$ & $* * *$ & $\begin{array}{c}0.0411 \\
(2.0055)\end{array}$ & * & $\begin{array}{c}0.0364 \\
(1.8095)\end{array}$ & \\
\hline $\log ($ Ret. Mat $) 2$ & $\begin{array}{c}0.0377 \\
(1.1664)\end{array}$ & & $\begin{array}{c}0.0628 \\
(2.2821)\end{array}$ & * & $\begin{array}{c}0.0396 \\
(1.4350)\end{array}$ & & $\begin{array}{c}0.0832 \\
(7.0759)\end{array}$ & $* * *$ & $\begin{array}{c}0.0901 \\
(7.6160)\end{array}$ & $* * *$ \\
\hline $\log \left(\right.$ Ret. MO) ${ }^{*} \log ($ Ret. Kl) & $\begin{array}{c}-0.1451 \\
(-1.7829)\end{array}$ & & $\begin{array}{c}-0.1304 \\
(-2.0100)\end{array}$ & * & $\begin{array}{c}-0.0992 \\
(-1.6051)\end{array}$ & & $\begin{array}{c}0.0067 \\
(0.0939)\end{array}$ & & $\begin{array}{c}0.0196 \\
(0.2831)\end{array}$ & \\
\hline $\log \left(\right.$ Ret. MO) ${ }^{*} \log ($ Ret. Mat) & $\begin{array}{l}-0.0807 \\
(-0.7073)\end{array}$ & & $\begin{array}{c}-0.0522 \\
(-0.6143)\end{array}$ & & $\begin{array}{c}-0.0444 \\
(-0.5386)\end{array}$ & & $\begin{array}{c}-0.0421 \\
(-1.6028)\end{array}$ & & $\begin{array}{c}-0.0266 \\
(-0.9892)\end{array}$ & \\
\hline $\log \left(\right.$ Ret. Kl ${ }^{*} \log ($ Ret. Mat) & $\begin{array}{l}-0.0112 \\
-0.01472\end{array}$ & & $\begin{array}{l}-0.0149) \\
-0.0196 \\
(-0.3075)\end{array}$ & & $\begin{array}{l}-0.0240 \\
-0.0240 \\
(-0.38909\end{array}$ & & $\begin{array}{c}-0.1548 \\
-(-40984)\end{array}$ & $* * *$ & $\begin{array}{r}-0.1663 \\
-4.4007\end{array}$ & $* * *$ \\
\hline Constant & $\begin{array}{l}18.5647 \\
(1.2624)\end{array}$ & & $\begin{array}{c}6.7313 \\
(0.7538)\end{array}$ & & $\begin{array}{l}17.0763 \\
(1.9073)\end{array}$ & & $\begin{array}{l}-15.2714 \\
(-1.4504)\end{array}$ & & $\begin{array}{c}-2.1894 \\
(-0.2032)\end{array}$ & \\
\hline Share MO & & & & & & & & & & \\
\hline Log(Vol Sewage Collected) & & & $\begin{array}{c}1.1654 \\
(2.1324)\end{array}$ & * & $\begin{array}{c}1.1654 \\
(2.1324)\end{array}$ & * & $\begin{array}{c}0.1441 \\
(1.0747)\end{array}$ & & $\begin{array}{c}0.1474 \\
(1.1378)\end{array}$ & \\
\hline Log(Vol Sewage Treated $)$ & & & $\begin{array}{c}0.1503 \\
(0.4744)\end{array}$ & & $\begin{array}{c}0.1503 \\
(0.4744)\end{array}$ & & $\begin{array}{c}-0.0075 \\
(-0.0980)\end{array}$ & & $\begin{array}{c}0.0012 \\
(0.0163)\end{array}$ & \\
\hline Log(Vol Water Produced) & & & $\begin{array}{l}-1.6243 \\
(-4.3165)\end{array}$ & $* * *$ & $\begin{array}{r}-1.6243 \\
(-4.3165)\end{array}$ & **** & $\begin{array}{c}-0.0963 \\
(-1.0620)\end{array}$ & & -0.1104 & \\
\hline Log(Ret. MO) & & & $\begin{array}{c}(-4.3163) \\
-1.3323 \\
(-3.2482)\end{array}$ & ** & $\begin{array}{c}-(-4.3163) \\
-1.3323 \\
(-3.2482)\end{array}$ & $* *$ & $\begin{array}{c}-0.1077 \\
(-1.0738)\end{array}$ & & $\begin{array}{c}-0.0005 \\
(-0.0052)\end{array}$ & \\
\hline $\log ($ Ret. Kl) & & & $\begin{array}{l}-0.2482) \\
-0.1355 \\
(0.4620)\end{array}$ & & -0.1355 & & -0.8791 & $* * *$ & -0.9503 & $* * *$ \\
\hline Log(Ret. Mat) & & & $\begin{array}{l}-0.40204 \\
-0.1204 \\
(-0.2981)\end{array}$ & & $\begin{array}{l}-0.1204) \\
-0.1204 \\
(-0.2981)\end{array}$ & & $\begin{array}{c}-3.9030) \\
0.6457 \\
(8.4868)\end{array}$ & $* * *$ & $\begin{array}{c}0.7354 \\
(9.5616)\end{array}$ & $* * *$ \\
\hline Constant & & & $\begin{array}{l}25.8339 \\
(5.3572)\end{array}$ & $* * *$ & $\begin{array}{l}25.8339 \\
(5.3572)\end{array}$ & $* * *$ & $\begin{array}{c}1.6246 \\
(1.1515)\end{array}$ & & $\begin{array}{c}-0.0251 \\
(-0.0172)\end{array}$ & \\
\hline Share Mat & & & & & & & & & & \\
\hline Log(Vol Sewage Collected) & & & $\begin{array}{c}0.1106 \\
(1.1908)\end{array}$ & & $\begin{array}{c}0.1106 \\
(1.1908)\end{array}$ & & $\begin{array}{c}-0.0532 \\
(-1.5247)\end{array}$ & & $\begin{array}{c}-0.0538 \\
(-1.5514)\end{array}$ & \\
\hline Log(Vol Sewage Treated) & & & $\begin{array}{c}0.0435 \\
(0.8071)\end{array}$ & & $\begin{array}{c}0.0435 \\
(0.8071)\end{array}$ & & $\begin{array}{c}0.0161 \\
(0.7972)\end{array}$ & & $\begin{array}{c}0.0180 \\
(0.8985)\end{array}$ & \\
\hline Log(Vol Water Produced $)$ & & & $\begin{array}{l}-0.2018 \\
(-3.1535)\end{array}$ & ** & $\begin{array}{l}-0.2018 \\
(-31535)\end{array}$ & $* *$ & $\begin{array}{c}0.0447 \\
(1.8774)\end{array}$ & & $\begin{array}{c}0.0435 \\
(1.8361)\end{array}$ & \\
\hline Log(Ret. MO) & & & $\begin{array}{c}-0.2205 \\
(-3.1613)\end{array}$ & $* *$ & $\begin{array}{l}-0.2205 \\
(-3.1613)\end{array}$ & $* *$ & $\begin{array}{c}-0.0421 \\
(-1.6028)\end{array}$ & & $\begin{array}{c}-0.0266 \\
(-0.9892)\end{array}$ & \\
\hline Log(Ret. Kl) & & & $\begin{array}{c}-0.0339) \\
(-0.6790)\end{array}$ & & $\begin{array}{c}-0.0339 \\
(-0.6790)\end{array}$ & & $\begin{array}{c}-0.1548 \\
(-4.0984)\end{array}$ & $* * *$ & $\begin{array}{c}-0.1663 \\
(-4.4007)\end{array}$ & $* * *$ \\
\hline Log(Ret. Mat) & & & $\begin{array}{c}0.0077 \\
0.07121)\end{array}$ & & $\begin{array}{c}0.0077 \\
0.07121)\end{array}$ & & $\begin{array}{c}0.1664 \\
(70759)\end{array}$ & $* * *$ & $\begin{array}{c}0.1802 \\
(76160)\end{array}$ & $* * *$ \\
\hline Constant & & & $\begin{array}{c}4.0042 \\
(4.8841)\end{array}$ & $* * *$ & $\begin{array}{c}4.0042 \\
(4.8841)\end{array}$ & $* * *$ & $\begin{array}{c}0.1223 \\
(0.3499)\end{array}$ & & $\begin{array}{c}-0.1252 \\
(-0.3506)\end{array}$ & \\
\hline Semester Dummies & Yes & & No & & Yes & & No & & Yes & \\
\hline Observations & $1.5 \mathrm{e}+03$ & & $1.5 \mathrm{e}+03$ & & $1.5 \mathrm{e}+03$ & & $1.5 \mathrm{e}+03$ & & $1.5 \mathrm{e}+03$ & \\
\hline LR chi2 & & & $9.3 e+03$ & & $1.1 \mathrm{e}+04$ & & $7.0 \mathrm{e}+03$ & & $7.7 \mathrm{e}+03$ & \\
\hline Log-Lik. & $-1.1 e+03$ & & $-6.1 e+03$ & & $-6.0 e+03$ & & $-6.1 \mathrm{e}+03$ & & $-6.1 \mathrm{e}+03$ & \\
\hline R2 Adjusted & 0.8776 & & & & & & & & & \\
\hline
\end{tabular}


coefficient is noted for the logarithm of the quantity of water produced to the square, as well as the coefficient associated with the interaction between the quantity of water produced and the volume of sewage treated.

In terms of marginal costs, the figures below show the estimated marginal costs.

Figure 2

Marginal Cost of the Water

Marginal Cost $1 \mathrm{~m}^{3}$ Water

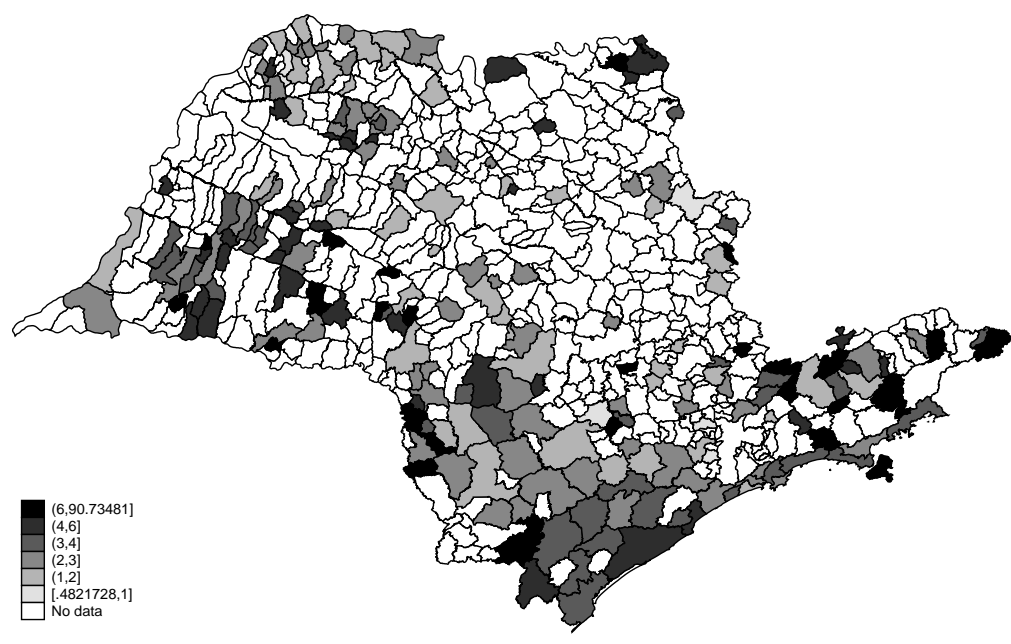

Maximum CMg estimated by city

Some important characteristics can be highlighted by observing figures 2,3 e 4. First, we note that in all cases positive marginal costs are calculated for water production, in the municipalities in which we have sufficient information to calculate the marginal costs. However, when we move on to the marginal costs analysis for sewage -- both collected and treated -- we largely observe negative marginal costs. This may be because we have high collinearity between the water and sewage measures (or between the collected and treated sewage measures), and thus we cannot consider this to be a suspicious point in relation to the estimates, as in the case discussed in the literature review regarding the criticisms of the results from Evans and Heckman.

We thus move on to the tests themselves, carried out with this methodology. 
Figure 3

Marginal Cost of the Collected Sewage Marginal Cost $1 \mathrm{~m}^{3}$ Collected Sewage

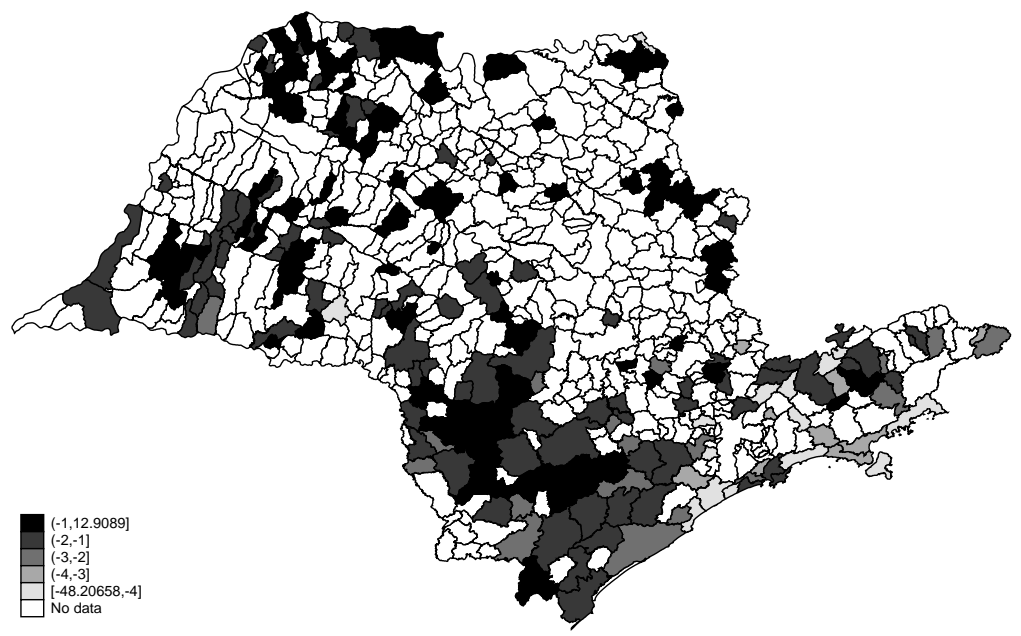

Maximum CMg estimated by city

Figure 4

Marginal Cost of the Treated Sewage Marginal Cost $1 \mathrm{~m}^{3}$ Treated Sewage
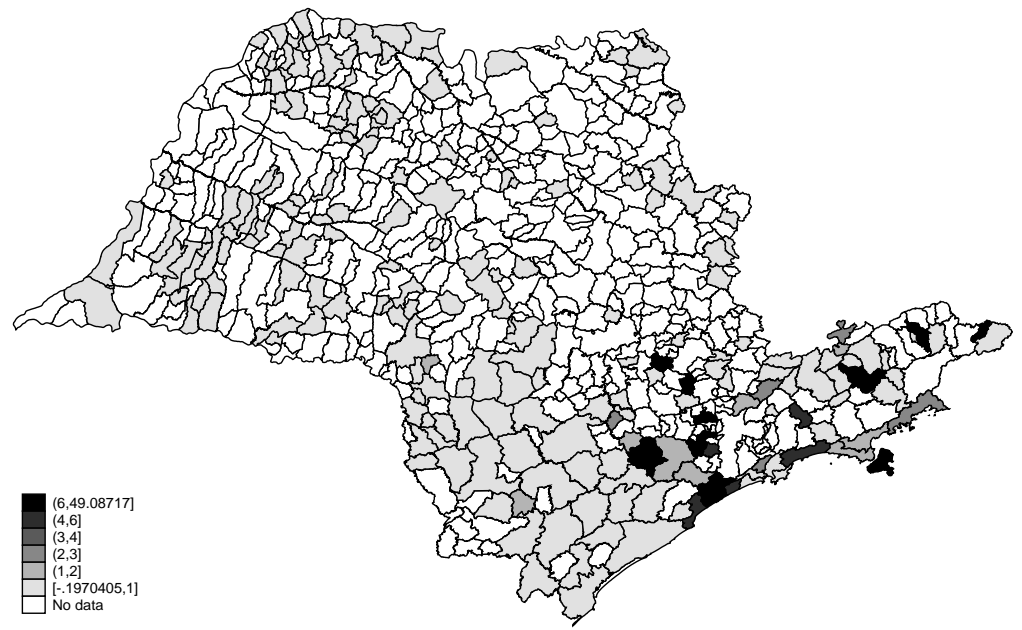

Maximum $\mathrm{CMg}$ estimated by city 


\subsection{Evans and Heckman Analysis}

The Evans and Heckman analysis followed here will be carried out in two stages. In the first of these the tests are carried out of the hypothesis for the estimated coefficients, and then the subadditivity test related with the economies of scale and scope is carried out. The first of the tests is the so-called additivity test. If this hypothesis is valid, we can construct a single product measure that is representative of the sector's scale and scope characteristics. Using the notation from the previous section, the test hypothesis would take the following form, for any products $k$ and $l$, and a factor of production $i$ :

$$
\delta_{k l}=-\beta_{k} \beta_{l}
$$

The results are presented in table 5, and we can note that it is not possible to use a single measure of sanitation services for the purposes of evaluating economies of scale.

Table 5

Additivity

\begin{tabular}{lcc}
\hline Test & EstF & P-Val \\
\hline Treated Sewage vs. Collected Sewage & 0,012 & 0,911 \\
Collected Sewage vs. Water & 0,746 & 0,388 \\
Water vs. Treated Sewage & 0,015 & 0,904 \\
\hline
\end{tabular}

Moreover, we can test the question of separability of the costs function, in the following way:

$$
\rho_{i l} \times \beta_{k}=\rho_{i k} \times \beta_{l}
$$

The results are in table 6 .

The results reject the possibility of separability in the costs function; that is, that the decision regarding the volume of services to be provided is separable in relation to the composition of the different services (water supplied. treated sewage. and collected sewage). That is. we need to analyze the characteristics of economies of scale and scope in the sanitation sector with greater care. The next step is to replicate the analysis of the Evans and Heckman simulation. For this we will separate 
Table 6

Separability

\begin{tabular}{lcc}
\hline Hypothesis & F Statistic & P-Val \\
\hline Treated Sewage and Collected Sewage (Eq-Personnel Share) & 0,064 & 0,801 \\
Water and Collected Sewage (Eq-Personnel Share) & 0,721 & 0,396 \\
Water and Treated Sewage (Eq-Personnel Share) & 0,033 & 0,856 \\
Treated Sewage and Collected Sewage (Eq-Materials Share) & 0,179 & 0,672 \\
Water and Collected Sewage (Eq-Materials Share) & 1,001 & 0,317 \\
Water and Treated Sewage (Eq-Materials Share) & 0,029 & 0,864 \\
\hline
\end{tabular}

the vector of quantities produced into two parts. Let us suppose that product 1 corresponds to sewage - collection and treatment - and product 2 corresponds to water production. $\mathbf{Q}_{t}^{*}=\left(Q_{1 t}^{*}, Q_{2 t}^{*}\right)$ is the vector of goods produced in a particular year $t$. Moreover. also consider the vector $\mathbf{Q}_{M}=\left(Q_{1 M}, Q_{2 M}\right)=\left(\min Q_{1 t}^{*}, \min Q_{2 t}^{*}\right)$, which are the lowest values of the two products available in the sample. Let us consider two hypothetical companies. A and B. which produce the following quantities:

$$
\begin{gathered}
\mathbf{Q}_{A t}=\left(\phi Q_{1 t}+Q_{1 M}, \omega Q_{2 t}+Q_{2 M}\right) \\
\mathbf{Q}_{B t}=\left((1-\phi) Q_{1 t}+Q_{1 M},(1-\omega) Q_{2 t}+Q_{2 M}\right)
\end{gathered}
$$

In this case, $\omega$ and $\phi$ belong to an interval $[0,1]$, since the quantity observed would be equal to the production of the two hypothetical companies ${ }^{10}$. Constraining the domain in the function to the observed values, the two companies together produce:

$$
\begin{aligned}
& Q_{1 t}+2 Q_{1 M}=Q_{1 t}^{*} \\
& Q_{2 t}+2 Q_{2 M}=Q_{2 t}^{*}
\end{aligned}
$$

The authors restrict the analysis to the years in which $Q_{1 t}>Q_{1 t}^{*}-2 Q_{1 M}$ and $Q_{2 t}>Q_{2 t}^{*}-2 Q_{2 M}$. Moreover, another condition set by them is that each hypothetical company produces the quantities of goods in proportions between the minimum and maximum observed in the data. This imposed condition aims to prevent the translog function coefficients from being used to generate cost estimations

10 The author's intuition is to avoid conclusions for out-of-sample production. 
for hypothetical quantities that are very distant from those observed in the data sample.

Finally, consider the following definitions:

$$
\begin{gathered}
C_{A t}(\phi, \omega)=C\left(\mathbf{Q}_{A t}\right) \\
C_{B t}(\phi, \omega)=C\left(\mathbf{Q}_{B t}\right) \\
C_{t}^{*}=C\left(\mathbf{Q}_{t}^{*}\right)
\end{gathered}
$$

These are the levels of costs for the two companies, $A$ and $B$, with the previously estimated coefficients. and the quantity produced for each hypothetical company of each of the products. $C_{A t}$ and $C_{B t}$ are functions of $\phi$ and $\omega$ over $\mathbf{Q}_{A t}$ and $\mathbf{Q}_{B t}$ are constructed via these coefficients. The subadditivity will be obtained by calculating the following statistic for each one of the products:

$$
S u b(\phi, \omega)=\frac{C_{t}^{*}-C_{A t}(\phi, \omega)-C_{B t}(\phi, \omega)}{C_{t}^{*}}
$$

We can note that this statistic is still a function of $\phi$ and $\omega$. Next, the results from the grid of points corresponding to different values of $\phi$ and $\omega$, are presented with a difference of 0.1 between each value for the parameters. Again, $\phi$ refers to the proportion of the quantity of sewage produced and collected by company $\mathrm{A}$, and $\omega$ is the proportion of the water produced by the same company.

Table 7

SC Proportion lower than zero

\begin{tabular}{lcccccccccc}
\hline & $\omega=0,1$ & $\omega=0,2$ & $\omega=0,3$ & $\omega=0,4$ & $\omega=0,5$ & $\omega=0,6$ & $\omega=0,7$ & $\omega=0,8$ & $\omega=0,9$ & $\omega=1$ \\
\hline$\theta=0,1$ & 0,05 & 0,04 & 0,04 & 0,03 & 0,02 & 0,02 & 0,02 & 0,02 & 0,01 & 0,01 \\
$\theta=0,2$ & 0,05 & 0,05 & 0,04 & 0,04 & 0,03 & 0,03 & 0,02 & 0,02 & 0,02 & 0,01 \\
$\theta=0,3$ & 0,05 & 0,05 & 0,04 & 0,04 & 0,04 & 0,04 & 0,03 & 0,03 & 0,02 & 0,02 \\
$\theta=0,4$ & 0,04 & 0,04 & 0,04 & 0,04 & 0,04 & 0,04 & 0,04 & 0,03 & 0,03 & 0,02 \\
$\theta=0,5$ & 0,04 & 0,04 & 0,04 & 0,04 & 0,04 & 0,04 & 0,04 & 0,04 & 0,04 & 0,03 \\
$\theta=0,6$ & 0,03 & 0,03 & 0,04 & 0,04 & 0,04 & 0,04 & 0,04 & 0,04 & 0,04 & 0,04 \\
$\theta=0,7$ & 0,02 & 0,03 & 0,03 & 0,04 & 0,04 & 0,04 & 0,04 & 0,05 & 0,05 & 0,04 \\
$\theta=0,8$ & 0,02 & 0,02 & 0,02 & 0,03 & 0,03 & 0,04 & 0,04 & 0,05 & 0,05 & 0,05 \\
$\theta=0,9$ & 0,01 & 0,02 & 0,02 & 0,02 & 0,02 & 0,03 & 0,04 & 0,04 & 0,05 & 0,05 \\
$\theta=1$ & 0,01 & 0,01 & 0,01 & 0,02 & 0,02 & 0,02 & 0,03 & 0,03 & 0,04 & 0,05 \\
\hline
\end{tabular}


Table 8

Greater SC Value

\begin{tabular}{lcccccccccc}
\hline & $\omega=0,1$ & $\omega=0,2$ & $\omega=0,3$ & $\omega=0,4$ & $\omega=0,5$ & $\omega=0,6$ & $\omega=0,7$ & $\omega=0,8$ & $\omega=0,9$ & $\omega=1$ \\
\hline$\theta=0,1$ & 0,90 & 0,89 & 0,89 & 0,88 & 0,87 & 0,86 & 0,85 & 0,84 & 0,82 & 0,81 \\
$\theta=0,2$ & 0,90 & 0,90 & 0,90 & 0,89 & 0,88 & 0,88 & 0,87 & 0,86 & 0,85 & 0,83 \\
$\theta=0,3$ & 0,90 & 0,90 & 0,90 & 0,90 & 0,89 & 0,89 & 0,88 & 0,87 & 0,87 & 0,86 \\
$\theta=0,4$ & 0,90 & 0,90 & 0,90 & 0,90 & 0,90 & 0,89 & 0,89 & 0,89 & 0,88 & 0,87 \\
$\theta=0,5$ & 0,89 & 0,89 & 0,90 & 0,90 & 0,90 & 0,90 & 0,90 & 0,89 & 0,89 & 0,88 \\
$\theta=0,6$ & 0,88 & 0,89 & 0,89 & 0,89 & 0,90 & 0,90 & 0,90 & 0,90 & 0,90 & 0,89 \\
$\theta=0,7$ & 0,87 & 0,87 & 0,88 & 0,89 & 0,89 & 0,90 & 0,90 & 0,90 & 0,90 & 0,90 \\
$\theta=0,8$ & 0,85 & 0,86 & 0,87 & 0,88 & 0,88 & 0,89 & 0,90 & 0,90 & 0,90 & 0,90 \\
$\theta=0,9$ & 0,82 & 0,84 & 0,85 & 0,86 & 0,87 & 0,88 & 0,89 & 0,89 & 0,90 & 0,90 \\
$\theta=1$ & 0,79 & 0,81 & 0,82 & 0,84 & 0,85 & 0,87 & 0,88 & 0,89 & 0,89 & 0,90 \\
\hline
\end{tabular}

Figure 5

Economies of Scale

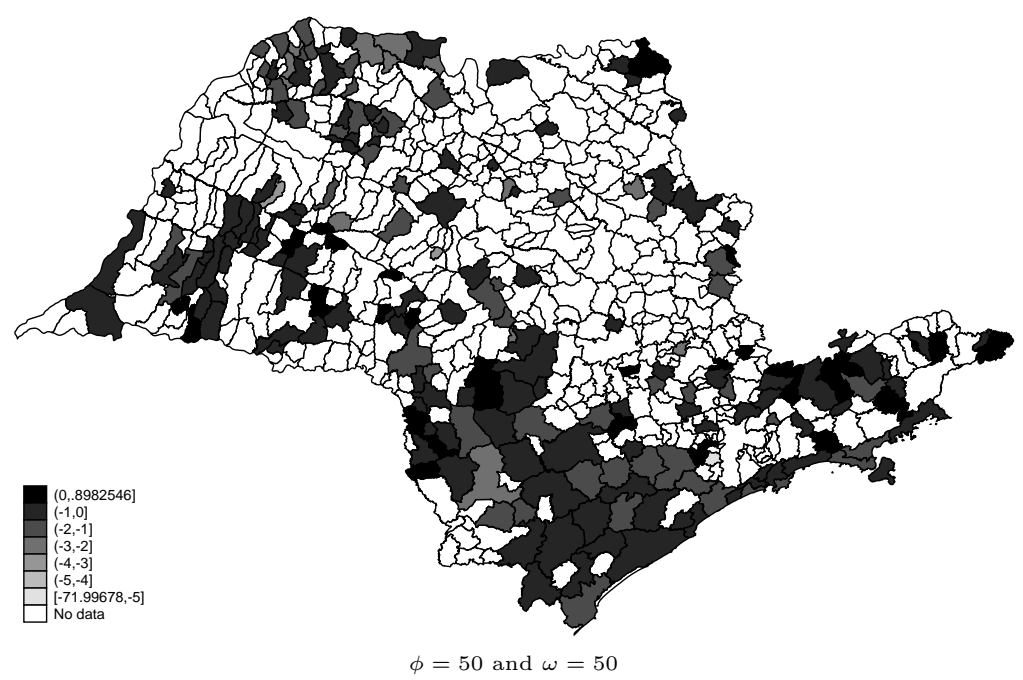

Based on the results above, we can note that the existence of diseconomies of scale is extremely rare in the cities served by SABESP, with almost all of them presenting negative values for the SC statistic - which indicates that the cost of production of the water and sewerage services, at the levels observed, is more economically provided by one company than two separate companies (in the case of figure 5 , with each of them producing exactly $50 \%$ of the total). 
Figure 6

Economies of Scope

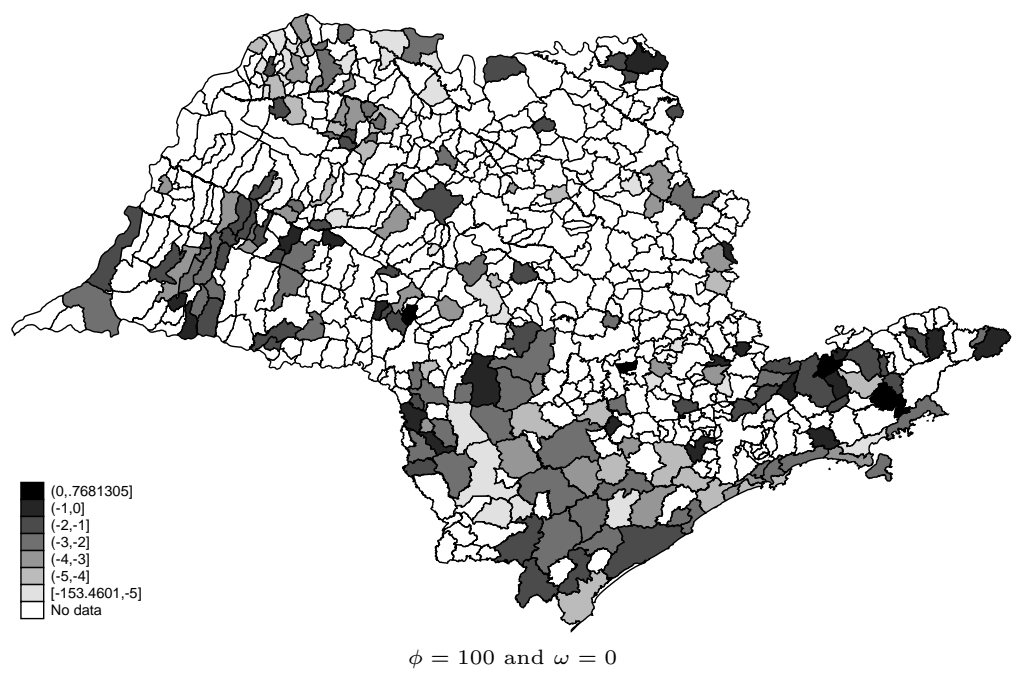

However, the evidence is weaker with relation to the economies of scope. Nevertheless, in the vast majority of the cities served by SABESP the joint provision of water and sewerage services within one company is cheaper than separation between two companies focused on different services - again, in the case of figure 6 , with one company focused on water services and another on sewerage services.

In light of the results, we can conclude that initiatives that aim towards the structural separation of integrated water operators tend to generate inefficiencies on the productive side. making the supply of the services less economical. In this section, we will analyze how the marginal costs behave in relation to the approved tariffs. The table below shows the tariffs per $\mathrm{m}^{3}$ of water. compared to the Social and Normal tariff values approved for SABESP.

Based on the results in table 9, we can note that, of 94 cities for which it was possible to carry out the comparison, 37 do not have any price per $m^{3}$ hat exceeds the marginal cost of supplying water. when we consider the social tariff. When we consider the normal tariff, this number falls to 22 cities. 


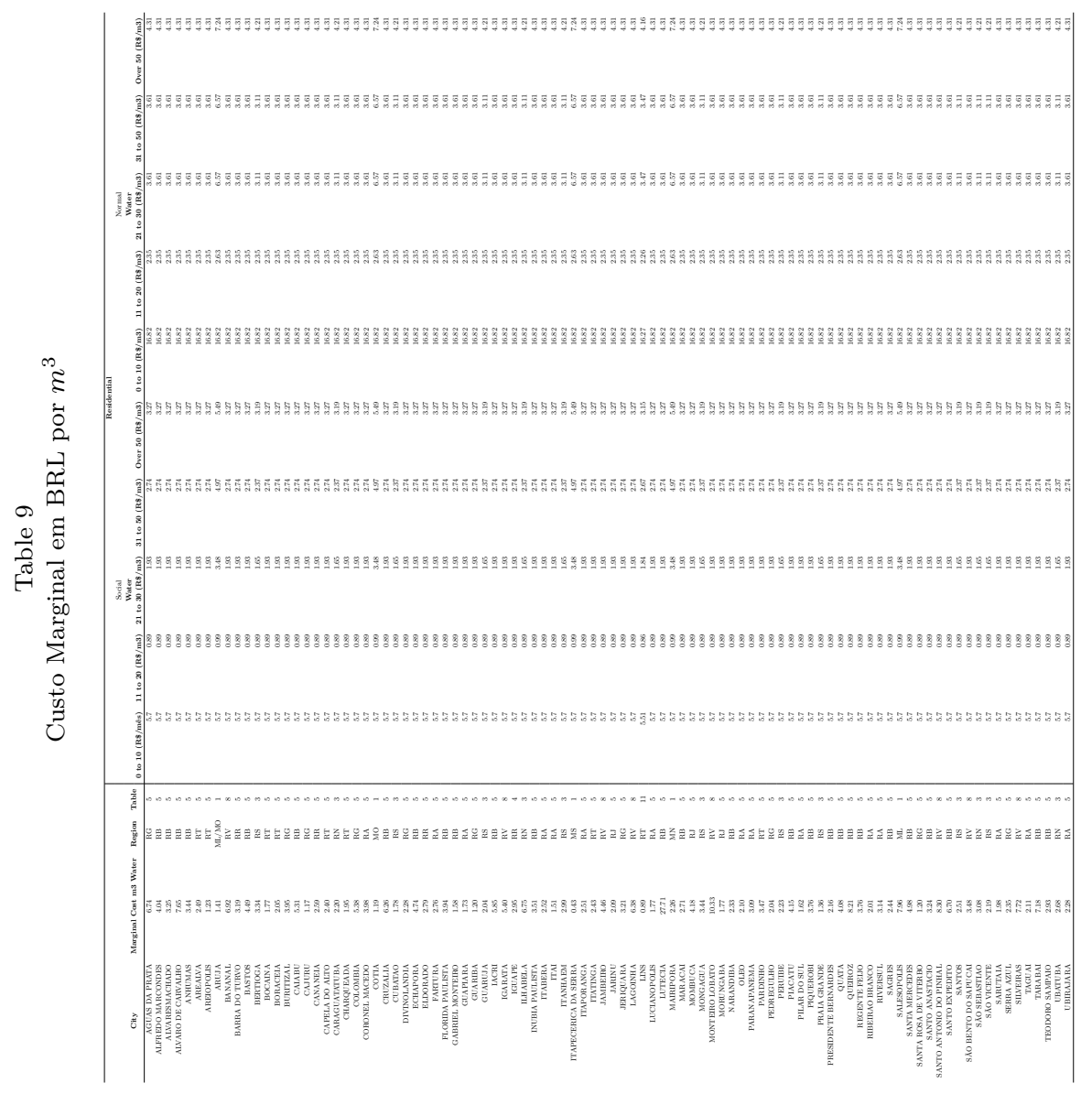




\section{Conclusion}

The aim of this project was to evaluate the existence of economies of scale and of scope in the sanitation sector. In this sector, after water collection, the next steps are water treatment, distribution to consumer points (residential. industrial. or commercial), followed by disposal into a drainage system. which may or may not be treated for returning into the natural cycle.

In Brazil, not all sanitation systems carry out these roles and not all carry them out within the same company. This raises a question, which we sought to answer in this study: from an economic viewpoint. would it be more efficient for all of these stages to be carried out within a single company?

In order to address this question, we aimed to apply the Evans and Heckman (1983) methodology to the context of the cities served by SABESP. For this, a database was constructed. which brought together internal information from the company and operational information collected from SNIS. Based on this information, a costs function was estimated, in the form of a transcendental logarithmic (translog) function, together with a system of equations representative of the demand by factors.

Based on these results, statistical hypothesis tests were carried out which were not very conclusive, given the low significance of some of the parameters. For this, the second part of the Evans and Heckman (1983) procedure was carried out, in which different product supply configurations are simulated, and in which two hypothetical companies supply the water and sewerage services separately.

From the results above we can note that the existence of diseconomies of scale is extremely rare in the cities served by SABESP, with almost all presenting negative values for the SC statistic - which indicates that the cost of production of the water and sewerage services, at the levels observed, is more economically provided by one company than two separate companies (in the case of figure 5, with each of them producing exactly $50 \%$ of the total). However, the evidence is weaker with relation to economies of scope. Nevertheless, in the vast majority of the cities served by SABESP, supplying water and sewerage services together within one company is cheaper than separately in two companies focused on different services - again, in 
the case of figure 6 . with one company focused on water services and another on sewerage services.

In light of the results, we can conclude that initiatives that aim to structurally separate integrated water operators tend to generate inefficiencies on the productive side making the supply of the services less economical.

Finally, in relation to the aims of the project, we believe that the results presented here can be used to elaborate an article to be published in a Brazilian journal with a selective editorial policy. Unfortunately, since part of the database had to be constructed with SNIS data, with semestrial periodicity and running up to 2010, this meant that the results from of the analysis lost a little of their interest for an international audience.

\section{References}

Abbott, M. \& Cohen, B. (2009). Productivity and efficiency in the water industry. Utilities Policy, 17(3):233-244.

Charnes, A., Cooper, W. W., \& Sueyoshi, T. (1988). A goal programming/constrained regression review of the bell system breakup. Management science, $34(1): 1-26$.

Cobb, C. W. \& Douglas, P. H. (1928). A theory of production. The American Economic Review, 18(1):139-165.

da Motta, R. S. \& Moreira, A. R. B. (2004). Eficiência e regulação no setor saneamento no brasil. Texto para Discussão 1084, IPEA, Rio de Janeiro.

Diewert, W. \& Wales, T. (1991). Multiproduct cost functions and subadditivity tests : A critique of the evans and heckman research on the u.s. bell system. UBC Departmental Archives 91-21, UBC Department of Economics.

Diewert, W. E. (1971). An application of the shephard duality theorem: A generalized leontief production function. The Journal of Political Economy, $79(3): 481-507$. 
Evans, D. S. \& Heckman, J. J. (1983). Multiproduct Cost Function Estimates and Natural Monopoly Tests for the Bell System, chapter 10, pages 253-282. Elsevier, Amsterdam, 1 edition.

Evans, D. S. \& Heckman, J. J. (1984). A test for subadditivity of the cost function with an application to the bell system. American Economic Review, 74(4):61523.

Evans, D. S. \& Heckman, J. J. (1986). A test for subadditivity of the cost function with an application to the bell system: Erratum. American Economic Review, $76(4): 856-58$.

Panzar, J. C. (1989). Technological determinants of firm and industry structure. In Schmalensee, R. \& Willig, R., editors, Handbook of Industrial Organization, volume 1 of Handbook of Industrial Organization, chapter 1, pages 3-59. Elsevier.

Pindyck, R. S. \& Rubinfeld, D. L. (2005). Microeconomics. Prentice-Hall, Inc., Upper Saddle River, NJ, USA, 5th edition.

Roller, L.-H. (1990). Proper quadratic cost functions with an application to the bell system. The review of economics and statistics, pages 202-210.

Salvanes, K. G. \& Tjøtta, S. (1998). A note on the importance of testing for regularities for estimated flexible functional forms. Journal of Productivity Analysis, 9(2):133-143.

Shin, R. T. \& Ying, J. S. (1992). Unnatural monopolies in local telephone. The RAND journal of economics, pages 171-183.

Sueyoshi, T. \& Anselmo, P. C. (1986). The evans and heckman subadditivity test: comment. American Economic Review, 76(4):854-55.

Tebbutt, T. (1998). Principles of Water Quality Control. Knopf Books for Young Readers, New York.

Viscusi, W. (2005). Economics of Regulation and Antitrust. Knopf Books for Young Readers, New York. 